\title{
Assessment of disaster preparedness at general hospitals in Al-Madinah Al-Munawarah Province, Western Region of Saudi Arabia
}

\author{
A study of pre intervention and post intervention test scores from 2017 to 2019
}

Anas Khan, MHA, SBEM, Jalal Alowais, ABGS, MMG, Abdullah Nofal, BSN, MHA, Tareef Alama, FRCPC, FACP.

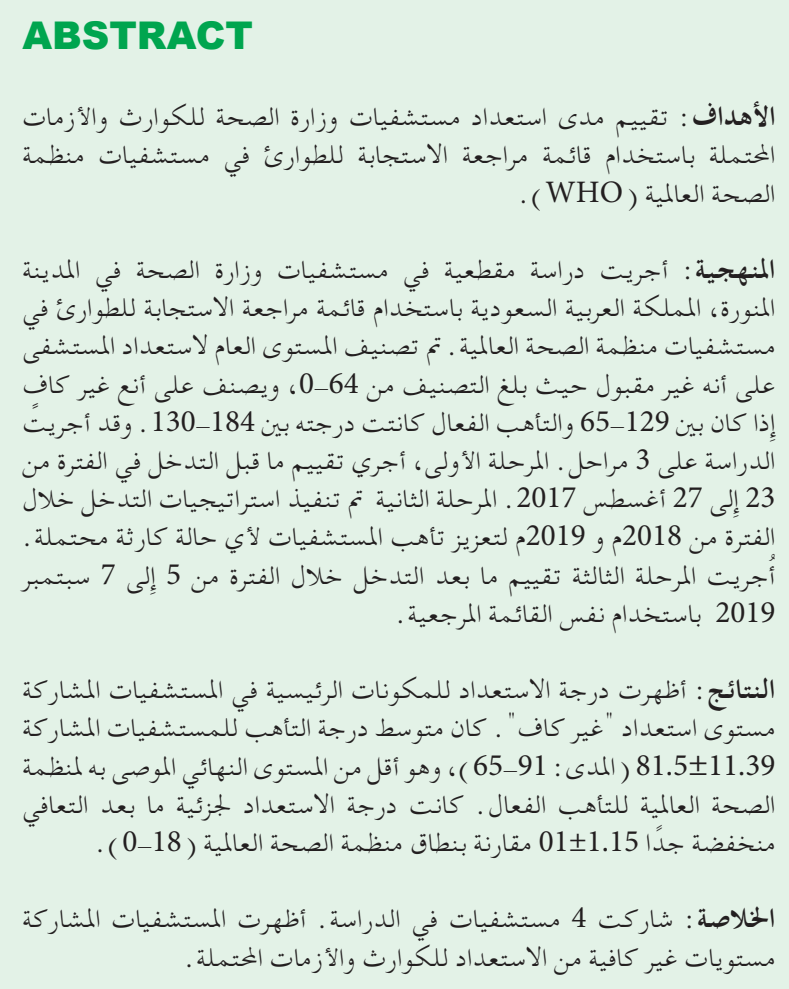

Objectives: To evaluate the Ministry of Health $(\mathrm{MoH})$ hospitals preparedness for potential disasters and crisis events using the World Health Organization (WHO) hospital emergency response checklist.

Methods: A cross-sectional study was conducted at $\mathrm{MoH}$ hospitals in Al-Madina, Saudi Arabia using the WHO hospital emergency response checklist. The overall level of hospital preparedness was categorized as unacceptable if the rating is between 0-64, insufficient if it is between 65-129 and effective preparedness if the score is between 130-184. The study conducted in 3 phases. First phase, the preintervention assessment was conducted from August 23 to 27, 2017. Second phase, intervention strategies were implemented between 2018 and 2019 to enhance the hospitals preparedness for any potential disaster situation. Third phase, the postintervention assessment was conducted from September 5 to 7, 2019, using with the same checklist.

Results: The preparedness score of key components at the participating hospitals showed an "insufficient" level of preparedness. The mean preparedness score of the participating hospitals was $81.5 \pm 11.39$ (range: 65-91), which is lower than the recommended WHO cut-off level of effective preparedness. The preparedness score of the post-recovery component was very low $01 \pm 1.15$ compared to the WHO range (0-18).

Conclusion: A total of 4 hospitals participated in the study. The participated hospitals showed insufficient levels of preparedness for potential disasters and crisis events.

Keywords: disaster, preparedness mass gathering, Madinah, Saudi Arabia.

Saudi Med J 2021; Vol. 42 (5): 537-542 doi: 10.15537/smj.2021.42.5.20200804

From the Department of Emergency Medicine (Khan), College of Medicine, King Saud University; from the Department of Surgery (Alowais), College of Medicine, Imam Muhammad ibn Saud Islamic University; from the Disaster Management Unit (Nofal), King Saud University Medical City; and from the Ministry of Health (Alama), Riyadh, Kingdom of Saudi Arabia.

Received 24th December 2020. Accepted 15th March 2021.

Address correspondence and reprint request to: Dr. Anas Khan, Associate Professor, Department of Emergency Medicine, College of Medicine \& University Medical City, King Saud University, Riyadh, Kingdom of Saudi Arabia.E-mail: anaskhan@ksu.edu.sa

ORCID ID: http://orcid.org/0000-0001-5075-7392 
I $n$ recent decades, the world has faced an increasing number of natural and human-made disasters, including tsunamis, earthquakes, terrorism, riots, complex emergencies, and the ongoing coronavirus disease 2019 (COVID-19) pandemic. Disasters generate enormous social and economic costs, especially for the vulnerable populations. ${ }^{1-4}$ Depending on the magnitude of the disaster and the vulnerability of the affected community, these events can claim many lives and devastate the economy and infrastructure of the community. In 2018, 315 natural disasters affected more than 68 million people and cost USD131 billion. This burden was not shared equally, inasmuch as Asia was the most susceptible continent, with $45 \%$ of all disaster events, $80 \%$ of the total deaths, and $76 \%$ of people affected. ${ }^{5}$ All hospitals are expected to have a preparedness plan for any predicted disaster. Healthcare disaster preparedness was introduced in the early $1990 \mathrm{~s}$ as a result of increasing numbers of events involving terrorism. ${ }^{6}$ Preparing the healthcare system to deal efficiently with all types of disasters is vital for providing a high standard of care and safe shelter to patients during disaster. ${ }^{7}$ Hospital disaster preparedness is "an ongoing process designed to guarantee hospital resilience and functionality during disasters and the ability to reduce overall mortality and morbidity." 1,3 A hospital's capability to deal with disasters and mass casualties relies on the availability of qualified staff, space, and equipment. ${ }^{1-4,7}$ Previous studies from different countries demonstrated that hospitals had difficulties in preparedness and in coping with or after disasters, ${ }^{1-4}$ because of a gross lack of formal training programs in emergency and disaster medicine. ${ }^{8}$ Standardization of disaster preparedness protocols in hospitals is urgently recommended. ${ }^{1-4}$ However, implementing international regulations to strengthen healthcare disaster preparedness and establishing the capacity for efficient disaster management are challenging. ${ }^{1}$ To ensure emergency preparedness and response development, the WHO has developed the hospital emergency response checklist to evaluate the preparedness of healthcare systems for dealing with disasters. ${ }^{4,9}$ More than 2 million pilgrims visit Makkah al-Mukarramah (Mecca) and Al-Madinah Al-Munawwarah (Medina) in Saudi Arabia during the Hajj season, which is one of the most highlighted mass gathering events globally. ${ }^{10}$ Therefore, hospital

Disclosure. Authors have no conflict of interests, and the work was not supported or funded by any drug company. strategies for disaster management are needed and must be improved.

A few studies in Saudi Arabia have been conducted to assess some aspects of disaster preparedness. ${ }^{11-14}$ Previous studies have demonstrated that Saudi Arabia is not yet well prepared for disasters and need to consider the WHO recommendations for adopting an international approach to disaster preparedness. ${ }^{15}$ Moreover, no published studies have addressed the preparedness of Saudi hospitals for disasters according to the WHO checklist. Therefore, our aim was to evaluate Al-Madinah Al-Munawwarah (Medina), Saudi Arabia Ministry of Health (MOH)-run hospitals' preparedness for potential disasters according to the WHO's hospital emergency response checklist.?

Methods. The study, which had a quasi-experimental design involving testing before and after interventions, according to the WHO hospital emergency response checklist was conducted at all 4 general hospitals overseen by the $\mathrm{MOH}$ in Al-Madinah Al-Munawwarah, Saudi Arabia. Al-Madinah is the second holiest city in Islam after Makkah and has a population of 1,512,724. ${ }^{16}$

We used PubMed and Embase databases to find previous related published articles.

We included MOH general hospitals in Al-Madinah Al-Munawwarah that are expected to be the primary points for receiving patients daily or in case of a disaster. While, private, military and MOH psychiatric, pediatric, and maternity hospitals were excluded in this study.

The study conducted in 3 phases. In the first phase the preintervention assessment was conducted from August 23 to 27, 2017 using the WHO's checklist.' Before the site visit, the hospital administrators were asked to prepare all the needed documents for the assessment team, which included officers responsible for the hospital's disaster activities.

In the second phase intervention strategies were implemented in the participating hospitals between 2018 and 2019 to enhance the hospitals preparedness for any potential disaster situation. In the third phase a post intervention assessment was conducted for all participating hospitals from September 5 to 7, 2019, using with the same checklist to assess the hospitals' preparedness for potential disasters.

WHO's checklist. The WHO hospital emergency response checklist ${ }^{11}$ includes current hospital-based emergency management principles and best practices and helps integrates priority action required for a rapid and effective response to a critical event. It consisted of 92 priority action items clustered in 9 key components: 
command and control (7 items), continuity of essential services (8 items), communication (9 items), post disaster recovery (9 items), triage (10 items), logistics and supply management (10 items), safety and security (11 items), surge capacity (13 items), and human resources (15 items). ${ }^{11}$

Each priority action item represents those that improve hospital preparedness for disasters and are documented as pending review, progressing, or completed. Each of the 92 items was evaluated by experts and scored as follows: $0=$ due for review; $1=$ in progress; and 2 completed. The total preparedness scores could thus range from 0 to 184 . The overall level of preparedness was unacceptable if the hospital's score was between 0 and 64 , insufficient if the score was between 65 and 129, and effective if the score was between 130 and $184 .{ }^{4}$

Intervention strategies. The study interventions were implemented immediately after the preintervention assessment. We applied the unified framework strategy that was published by the General Health Department of Emergency, Disaster, and Ambulance Transportation, Riyadh, Saudi Arabai to improve the readiness of hospitals to deal with various emergencies and disasters. This framework included guidelines and methods for hospitals to apply strategies that included mitigation and preparedness, response, and recovery plans.

Mitigation andpreparedness plans. Each participated hospital were developed and adopted a preventive measures plan. This plan mandates an analysis of the expected risk according to its nature, which includes disease vaccination and health awareness plans, safety protocols of health facilities, training, drills, preventive measures to control infection, and evacuation plans. Training was performed for personnel involved in responding to emergencies and disasters to increase their confidence and efficiency during any disaster situation. Annual drills were performed in the participating hospitals. The drill must cover all potential risks in the region while ensuring that each health facility conducts at least 2 drills each year so that the exercise identifies and addresses all expected risks in the facility.

Response plans. The framework provides care and management plan to victims of disaster and containment of the event and alerts, communication, and coordination between emergency committees and response teams across regions and governorates.

Recovery plan. The framework for recovery encompasses the facilities' post disaster support functions. This entails supporting the recovery of the community and building capacity, health recovery functions, infrastructure, housing, and resources.
Ethical considerations. This study was approved by the Institutional Review Board, College of Medicine, King Saud University (approval number E-19-4137), and it followed the Good Clinical Practice (GCP) ethical standards and principle of Helsinki Declaration.

Statistical analysis. We used the IBM SPSS statistics for windows, version 24.0 (IBM Corporation, Armonk, NY, USA) to perform statistical analysis of the data. A descriptive analysis (frequency, mean, and standard deviation) was used to describe hospital preparedness. A paired $t$ test was used to compare preintervention scores with postintervention scores.

Results. All 4 general hospitals in Al-Madinah were enrolled in the study. On the preintervention test, the preparedness scores of critical components at all 4 hospitals indicated a low preparedness level. The highest attained score was 91 out of 184, and the lowest was 66. On the postintervention test, the mean scores were significantly increased in all 4 hospitals (Table 1).

With regard to the key components of the WHO's checklist, the mean preparedness scores before the intervention were lower than those recommended by the WHO for sufficient preparedness. After the intervention, all scores increased significantly except those for continuity of essential services component which were not significant $(p=0.147)$. However, all postintervention scores are below the mean scores of WHO (Table 2).

On the preintervention test, all the participating hospitals mean preparedness score was $81.5 \pm 11.39$, which is lower than the recommended WHO cutoff level of adequate preparedness. On the postintervention test, the mean preparedness score of the 4 participating hospitals increased significantly to $157.00 \pm 19.74$ $(p<0.001)$.

The mean score for the post recovery component was very low $(1 \pm 1.15$; WHO range, 0 -18) before the intervention, whereas after the intervention, it increased significantly to $15.00 \pm 2.94(p<0.001$; Table 2$)$.

Discussion. For the WHO checklist and its key components, our study demonstrated that all the assessed hospitals before the intervention were insufficiently prepared for potential disasters. One of these hospitals, the Al Madinah Health Affairs, had a very marginal score, a clear depiction of it's structural and functional unpreparedness in managing an emergency, primarily due to its being the oldest healthcare facility in Al-Madinah Al-Munawwarah. In such case, infrastructural renovations were not a costeffective outcome. Hence, inter-hospital merger was 
Table 1 - Preintervention and postintervention test scores of the key preparedness components at four participating hospitals.

\begin{tabular}{|c|c|c|c|c|c|c|c|c|c|}
\hline \multirow[t]{2}{*}{ Key components } & \multirow{2}{*}{$\begin{array}{l}\text { Maximum } \\
\text { value for } \\
\text { each } \\
\text { component }\end{array}$} & \multicolumn{2}{|c|}{ Hospital 1} & \multicolumn{2}{|c|}{ Hospital 2} & \multicolumn{2}{|c|}{ Hospital 3} & \multicolumn{2}{|c|}{ Hospital 4} \\
\hline & & $\begin{array}{c}\text { Pre } \\
\text { intervention } \\
\text { test }\end{array}$ & $\begin{array}{c}\text { Post } \\
\text { intervention } \\
\text { test }\end{array}$ & $\begin{array}{c}\text { Pre } \\
\text { intervention } \\
\text { test }\end{array}$ & $\begin{array}{c}\text { Post } \\
\text { intervention } \\
\text { test }\end{array}$ & $\begin{array}{c}\text { Pre } \\
\text { intervention } \\
\text { test }\end{array}$ & $\begin{array}{c}\text { Post } \\
\text { intervention } \\
\text { test }\end{array}$ & $\begin{array}{c}\text { Pre } \\
\text { intervention } \\
\text { test }\end{array}$ & $\begin{array}{c}\text { Post } \\
\text { intervention } \\
\text { test }\end{array}$ \\
\hline Command and control & 14 & 8 & 13 & 5 & 12 & 7 & 13 & 4 & 7 \\
\hline Communication & 18 & 6 & 17 & 5 & 14 & 8 & 15 & 6 & 11 \\
\hline Safety and security & 22 & 7 & 20 & 12 & 20 & 11 & 18 & 9 & 12 \\
\hline Triage & 20 & 13 & 19 & 13 & 18 & 13 & 19 & 16 & 17 \\
\hline Surge capacity & 26 & 12 & 26 & 8 & 26 & 18 & 26 & 18 & 23 \\
\hline $\begin{array}{l}\text { Continuity of essential } \\
\text { services }\end{array}$ & 16 & 14 & 16 & 7 & 16 & 9 & 13 & 11 & 11 \\
\hline Human resources & 30 & 16 & 28 & 12 & 27 & 14 & 25 & 12 & 22 \\
\hline $\begin{array}{l}\text { Logistics and supply } \\
\text { management }\end{array}$ & 20 & 8 & 20 & 4 & 16 & 9 & 15 & 8 & 13 \\
\hline Postdisaster recovery & 18 & 2 & 18 & 0 & 16 & 2 & 15 & 0 & 11 \\
\hline Total scale score & 184 & 86 & 177 & 66 & 165 & 91 & 159 & 84 & 127 \\
\hline Mean scale score & 20.4 & 9.564 .48 & $19.67 \quad 4.72$ & $7.33 \quad 4.36$ & 18.335 .15 & $10.11 \quad 4.59$ & $17.67 \quad 4.87$ & $9.33 \quad 5.68$ & 14.115 .42 \\
\hline
\end{tabular}

Table 2 - Mean preintervention and postintervention test scores for preparedness key components.

\begin{tabular}{|c|c|c|c|c|}
\hline Key components & Preintervention test & Postintervention test & $P$-value & Reference range \\
\hline Command and control & 61.83 & $11.25 \quad 2.87$ & 0.009 & $0-14$ \\
\hline Communication & 6.251 .26 & 14.251 .250 & 0.008 & $0-18$ \\
\hline Safety and security & $9.8 \quad 2.21$ & 17.503 .77 & 0.033 & $0-22$ \\
\hline Triage & 13.51 .73 & 18.250 .96 & 0.032 & $0-20$ \\
\hline Surge capacity & 144.90 & 25.251 .50 & 0.031 & $0-26$ \\
\hline Continuity of essential services & 10.32 .97 & $14.00 \quad 2.45$ & 0.147 & $0-16$ \\
\hline Human resources & 13.51 .91 & 25.502 .65 & 0.002 & $0-30$ \\
\hline Logistics and supply management & 7.32 .21 & 16.002 .94 & 0.019 & $0-20$ \\
\hline Postdisaster recovery & 11.15 & $15.00 \quad 2.94$ & 0.001 & $0-18$ \\
\hline Total scale mean score & 81.511 .39 & $157.00 \quad 19.74$ & $<0.001$ & $0-184$ \\
\hline
\end{tabular}

deemed to be the most optimal recommendation. After the interventions were implemented, the preparedness level of the participating hospitals changed from insufficient level to practical. Moreover, our results showed significant increases in mean preparedness scores for all the key components except continuity of essential services. However, all post intervention scores are below the mean scores of WHO.

Overall, our findings were largely consistent with results reported by Ingrassia et $\mathrm{al}^{4}{ }^{4}$ who also used the WHO checklist. They evaluated 15 hospitals in different regions in Italy; of those hospitals, 12 were found to be insufficiently prepared for an emergency or a disaster. In 2013, Djalali et $\mathrm{al}^{2}$ compared hospital preparedness in Iran with that in Sweden in terms of functional capacity; they found that Iranian hospitals were at risk for poor disaster management, whereas Sweden's hospitals had a safe level of functional capacity for disaster management.

Moreover, in an international study, disaster management preparedness was assessed in the healthcare systems of the 27 countries in the European Union. The levels of preparedness among the countries were diverse; $68 \%$ of those countries showed an acceptable level of disaster management preparedness, but $32 \%$ had transitional levels, which means these countries 
could not function effectively during and after crises or disasters. ${ }^{17}$

A strong command and control system is indispensable for effective coordination of emergency operations on site. ${ }^{9}$ The mean score of the command and control component in our results demonstrated an unacceptable level of disaster preparedness in the preintervention test, which was inconsistent with the findings of Ingrassia et al. ${ }^{4}$ The majority of the hospitals in their study indicated an efficient preparedness level regarding command and control response. ${ }^{4}$ In our study, however, after the study interventions were implemented, our data showed that the mean score for command and control system increased significantly $(p=0.009)$.

Communication mechanisms are the foremost challenges facing healthcare systems during disasters and can adversely affect the functioning of entire response operations. ${ }^{18}$ Effective communication facilitates understanding between the parties and stakeholders, enables the prompt identification of gaps or defects in response systems, and boosts mutual problem solving. In our study, all 4 hospitals demonstrated insufficient preparedness in their communication mechanisms before the study interventions. Our results on communication mechanisms were similar to those reported from a comparative study conducted in Yemen in 2011 and repeated in 2015 to evaluate hospital disaster preparedness in Sana'a. That study showed unacceptable communication mechanisms in 2011 and unsatisfactory progress in the communication mechanism in 2015. ${ }^{19}$ In our study, on the post intervention test, the mean score of the communication mechanisms across all of the assessed hospitals changed significantly from a level indicating insufficient preparedness to one reflecting effective preparedness.

Furthermore, identifying a necessary protective safety and security measures plan is crucial in terms of gaps related to managing biological and chemically hazardous materials and epidemic outbreaks. In this study's pre intervention test, the mean score of safety and security revealed an unacceptable level of safety and security, which exposed the hospitals to a higher risk of functional failure during disasters, especially terror attacks. In comparison, the post intervention test indicated significant improvement in safety and security.

In contrast to the findings of Ingrassia et $\mathrm{al}^{4}{ }^{4}$ our preintervention test revealed that all assessed hospitals were insufficiently prepared to perform triage in scenarios of an increased number of fatalities. Triage systems for managing situations resulting in casualties should be adequate and in place. Emergency personnel should be trained in using the triage systems.

It is essential to evaluate the size of healthcare institutions and surge capacity in view of the distribution of disaster casualties among local hospitals during a potential disaster. Therefore, surge capacity is an integral element of a healthcare institution's preparedness. ${ }^{3,20,21}$ In fact, our preintervention test results confirmed insufficient surge capacity in the four hospitals. These results were similar to findings reported by Ingrassia et al. ${ }^{4}$

A well-planned hospital disaster strategy should include provisions to ascertain and maintain essential hospital services and the resources needed to guarantee the continuity of these vital services, and an evacuation plan that aims to preserve the continuity of care should be in place. $^{22}$ Our preintervention test revealed that none of the hospitals were sufficiently prepared to ensure continuity of essential services $(10.25 \pm 2.97$ out of a possible score of 16) to support hospital needs during disasters. Furthermore, the preintervention and postintervention scores for this component did not differ significantly $(p=0.147)$. Thus, intervention strategies must be devised to ensure the continuity of essential services during disaster events.

Scores on the preintervention test indicated that the preparedness for maintaining human resources and logistics and supply management were unacceptable according to the WHO checklist, but the post intervention test indicated significant improvement. Hospitals are responsible for defining the human resource logistic needs of the healthcare system for emergency disasters. Training, knowledge, and competencies should be delineated by the $\mathrm{MOH}$, grounded in national needs assessments and anticipated risk analysis.

Preparedness for post disaster recovery was inferior across the 4 assessed hospitals (one out of a possible score of 18) according to scores on the preintervention test, but it was significantly improved by the time of the postintervention test $(p<0.001)$.

Our study evaluation and findings should encourage further planned activities to guarantee a more extensive and ample analysis of all hospitals. National guidelines, standards, and procedures are needed to improve and augment hospital disaster preparedness. To improve the capacity for emergency and disaster preparedness and response, the existing trends and statistics must be evaluated and further studies must be conducted.

Study limitations. This investigation was the first interventional study in which an internationally validated and standardized tool (the WHO checklist) was 
used to evaluate disaster preparedness in all $\mathrm{MOH}$-run hospitals in Al-Madinah. The only limitation was that we did not consider the informational background and the participating hospital's socioeconomic conditions, which may confound the findings with regard to the levels of preparedness.

In conclusions, the results of this study showed that the participating hospitals significantly changed their disaster preparedness levels from insufficient to adequate. Nonetheless, their ability to ensure continuity of essential services during disasters needs prompt improvement.

Acknowledgment. This work was supported by the College of Medicine Research Center, Deanship of Scientific Research, King Saud University, Riyadh, Saudi Arabia.

\section{References}

1. Yasuyuki S, Bhattcharyay R, Tomoaki KO. Aggregate impacts of natural and man-made disasters-a quantitative comparison. Tokyo (JP): Research Institute of Economy, Trade and Industry; 2011.

2. Djalali A, Castren M, Khankeh H, Gryth D, Radestad M, Öhlen G, Kurland L. Hospital disaster preparedness as measured by functional capacity: a comparison between Iran and Sweden. Prehosp Disaster Med 2013; 28: 454.

3. European Union/ECHO. European Commission, Commission Staff Working Document, Overview of Natural and Man-made Disaster Risks the European Union may face, Brussels: European Union/ECHO; 2017.

4. Ingrassia PL, Mangini M, Azzaretto M, Ciaramitaro I, Costa L, Burkle Jr FM, Della Corte F, Djalali A. Hospital Disaster Preparedness in Italy: a preliminary study utilizing the World Health Organization Hospital Emergency Response Evaluation Toolkit. Minerva Anestesiol 2016; 82: 1259-1266.

5. OCHA. Natural Disasters 2018 [cited 2018]. Available from: https://reliefweb.int/report/world/natural-disasters-2018.

6. Toner E. Healthcare preparedness: Saving Lives. Health Secur 2017; 15: 8-11.

7. Shalhoub AA, Khan AA, Alaska YA. Evaluation of disaster preparedness for mass casualty incidents in private hospitals in Central Saudi Arabia. Saudi Med J 2017; 38: 302-306.

8. Naser WN, Saleem HB. Emergency and disaster management training; knowledge and attitude of Yemeni health professionalsa cross-sectional study. BMC Emerg Med 2018; 18: 23.

9. World Health Organization. Hospital emergency response checklist-An all-hazards tool for hospital administrators and emergency managers. [cited 2011]. Available from: http://www. euro.who.int/data/assets/pdf_file/0020/148214/e95978.pdf.
10. Shujaa A, Alhamid S. Health response to Hajj mass gathering from emergency perspective, narrative review. Turk J Emerg Med 2016; 15: 172-176.

11. Alshehri B. Emergency nurses' preparedness for disaster in the Kingdom of Saudi Arabia. Journal of Nursing Education and Practice 2017; 7: 6.

12. Al-Shareef AS, Alsulimani LK, Bojan HM, Masri TM, Grimes JO, Molloy MS, Ciottone GR. Evaluation of hospitals' disaster preparedness plans in the Holy City of Makkah (Mecca): a cross-sectional observation study. Prehosp Disaster Med 2017; 32: 33-45.

13. Nofal A, Alfayyad I, Khan A, Al Aseri Z, Abu-Shaheen A. Knowledge, attitudes, and practices of emergency department staff towards disaster and emergency preparedness at tertiary health care hospital in central Saudi Arabia. Saudi Med J 2018; 39: 1123-1129.

14. Alzahrani F, Kyratsis Y. Emergency nurse disaster preparedness during mass gatherings: a cross-sectional survey of emergency nurses' perceptions in hospitals in Mecca, Saudi Arabia. BMJ Open 2017; 7: e013563.

15. Alraga SM. An investigation into disaster health management in Saudi Arabia. J Hosp Med Manage 2017; 3: 18.

16. Ministry of National Guard - Health Affairs. About Madinah. [cited 2020 December 07]. Available from: https:// ngha.med.sa/English/MedicalCities/AlMadinah/Pages/ AboutAlMadinahAlMunawwarah.aspx

17. Djalali A, Della Corte F, Foletti M, Ragazzoni L, Gallardo AR, Lupescu O, Arculeo C, von Arnim G, Friedl T, Ashkenazi M, Fischer P. Art of disaster preparedness in European Union: A survey on the health systems. PLOS Currents Disasters 2014; Dec 17: 1-17.

18. Matsumoto H, Motomura T, Hara Y, Masuda Y, Mashiko K, Yokota H, Koido Y. Lessons learned from the aeromedical disaster relief activities following the great East Japan earthquake. Prehosp Disaster Med 2013; 28: 166.

19. Aladhrai SA, Djalali A, Della Corte F, Alsabri M, El-Bakri NK, Ingrassia PL. Impact of the 2011 revolution on hospital disaster preparedness in Yemen. Disaster Med Public

20. Sheikhbardsiri H, Raeisi AR, Nekoei-Moghadam M, Rezaei F. Surge Capacity of Hospitals in Emergencies and Disasters With a Preparedness Approach: A Systematic Review. Disaster Med Public Health Prep 2017; 11: 612-620.

21. Einav S, Hick JL, Hanfling D, Erstad BL, Toner ES, Branson RD, Kanter RK, Kissoon N, Dichter JR, Devereaux AV, Christian MD. Surge capacity logistics: care of the critically ill and injured during pandemics and disasters: CHEST consensus statement. Chest 2014; 146: e17S-e43S.

22. Ozoilo KN, Pam IC, Yiltok SJ, Ramyil AV, Nwadiaro HC. Challenges of the management of mass casualty: lessons learned from the Jos crisis of 2001. World J Emerg Surg 2013; 8: 1-5. 